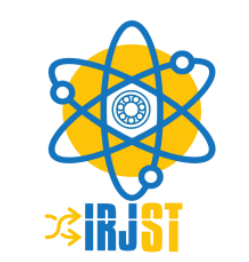

Available online at https://www.irjst.com/

International Research Journal of Science and Technology

ISSN: 2707-3955

DOI: https://doi.org/10.46378/irjst.2020.010203

\title{
Relationship between Emotional Intelligence, Coping Styles and Psychopathology among Medical Students in District Peshawar
}

\section{Naveeda Sarwar*, Saima Abid, Ghulam Sarwar Khan and Adnan Sarwar}

Pak International Medical College, Peshawar, Pakistan

$\begin{array}{lll}\text { Manuscript Status } \\ \text { Received } \quad: & \text { January } 2020 \\ \text { Accepted } \quad: & \text { March } 2020 \\ \text { Published } \quad: & \text { March } 2020\end{array}$

Key Words

Coping style

Emotional intelligence

Medical colleges

Peshawar

Psychopathology

Public and private

\begin{abstract}
This study was undertaken to assess the relationship between Emotional Intelligence, Coping Styles and Psychopathology among medical students in district Peshawar, Pakistan.200 participants were recruited for data collection through purposive convenient sampling. Cross sectional research design was used. The age range of participants was 18 to 25 years with the participation of male $(n=117)$ and female $(n=83)$. Subjects were selected from public and private medical colleges. To determine the role of Demographic variables, age, gender, father income, college and self-reports measures of Emotional Intelligence scale Brief Cope Inventory and Psychopathic deviation were used. Correlation, t-test and regression analysis was applied for data analysis. The results revealed that female had high emotional intelligence as compared to male.it also showed from the results that those who have low emotional intelligence had more psychopathological characteristics. The results also revealed that those students who had poor emotional intelligence used maladaptive coping styles. Hence, it was inferred from the study that there is significant positive correlation between emotional intelligence, coping styles and psychopathology. Cross sectional nature of the study, use of self-report measures and non-probability sampling was the limitation of the study.
\end{abstract}

Copyright (C) 2020: Naveeda Sarwar, Saima Abid, Ghulam Sarwar Khan and Adnan Sarwar. This is an open access distribution, and reproduction in any medium, provided Access article distributed under the Creative Commons Attribution License the original work is properly cited License, which permits unrestricted use.

Citation: Naveeda Sarwar, Saima Abid, Ghulam Sarwar Khan and Adnan Sarwar. "Relationship between Emotional Intelligence, Coping Styles and Psychopathology among Medical Students in District Peshawar", International Research Journal of Science and Technology, 1 (2) 88-95, 2020.

\section{Introduction}

United States of Accreditation Council for Graduate clinical schooling (ACGME) has defined 6 capabilities of a medical graduate: patient carefulness, proficiency, structures based practice, interactive and communication skills, scientific information and training based mastering [1].

*Corresponding Author: Naveeda Sarwar

Pak International Medical College, Peshawar, Pakistan

Email : naveedasarwar6@gmail.com
Most of the abilities which can be highlighted within the above capabilities are components of EI. Several researches were performed to evaluate the EI and its associates amongst clinical students and other fitness care specialists [2]. Despite the fact that feelings are recognized to be a prevalent phenomenon, cultural elements can strongly have an impact on the ways wherein they're being experienced/perceived, conveyed, and controlled [3]. South Asia (SA), at present there are numerous research on EI of medical undergraduates (UGs) and postgraduates (PGs) from $\mathrm{SA}$, which has discovered the associations between EI, 
compassion and strain. Currently an increasing number of researches pointed on the co-relation among educational overall performance and EI from SA [4].

Emotional intelligence in scientific circle is the major topic of concern. Nemiah and colleagues (1970) coined the term alexithymia (failure to express feelings) for the first time, and it seems to be inversely related to emotional intelligence [5]. EI has also been related to stress and coping. Via growing their emotional intelligence individuals can emerge as greater dynamic and prosperous by anything they do, and benefit others turn out to be greater useful and a success also. The techniques and consequences of emotional intelligence progress additionally comprise numerous features to recognized and lessen strainin place of individuals and consequently corporations - through using diminishing struggle; helping information and relationships; and nurturing balance, continuousness, and coherence. Love and spirituality is not the last standard but have first importance which links to emotional intelligence [6]. Coping is defined by [7] the mental and behavioral components are used by the individual to come across daily requirements and overcome difficulties', which are shaped by their internal and external domains, to maintain them within limits and decrease stress and tension. Usually coping is to understand the person beside poor physical and psychological outcomes.

The coping paradigm is an important concept for evaluation of an individual adoptable and nonadoptable style of stress management .Many measures has been used to assess the population. Ways of Coping questionnaires (WCQ), coping strategies inventory (CSI) and Brief Cope Scale (BCS) are some of the measured revealed by literature.

Psychopathy is amongst one of the utmost frequently researched and first-class proven .Psychiatric conditions, together with sociopathic and delinquent personality disease [8] For hundreds of years, many theorists from unique international locations and cultures have developed various medical descriptions that emphasize or encompass unique symptoms or personality trends based totally upon their character reviews [8]. In spite of the abundance of studies and use in criminal arenas, there is still a lack of agreement at the center features of psychopathy [8].

In a co relational study, found the associations among different regulatory strategies of emotions including taking, preventing, problem solving, judgmental, thinking, and suppression and symptoms of four mental health problems like anxiety, depression, eating, and drug abuse disorders [9]. The studied documented Meta-analysis asses of 241 effect sizes from 114 researches that studied the relations amongst temperament, emotional parameter and psychopathology. Guiding strategies were consistent with internalizing disorder than externalizing disorder.

It was discovered that high EI predicted the use of adaptive coping styles during the experiences of not only stress but sadness, anger, fear, shame, and jealousy, while maintaining the experience of joy [10]. These results have important implications in the mental health field where emotions show a crucial role in the maintenance and development of illness. However, the literature cited above especially from EI, coping styles and psychopathology domain is backdrop justification for establishing the rationale of studying to find the association between three variables related to medical students. The study significance was to create awareness about comorbidity of psychopathology and emotional intelligence among medical students. It were helpful to know the ratio of emotional intelligence and coping styles in male vs. female, as female are lower emotional tolerance and more vulnerable to these pathological disorders when having maladaptive coping styles.

To suggest a comprehensive plan of counseling and therapy for those students who have maladaptive and poor emotional intelligence. The most important of all is that region of Pakistan very few studies have been conducted on this topic. The three variable were not studied as a communal variable as were studied in this study. As per the generational population the medical professional were considered as soul of the society. In order to make a good professional there valuations of coping abilities, emotional intelligence and psychopathic characteristics were needed to be assessed.

Therefore, the current study was planned with the following objectives:

1. To determine the emotional intelligence of medical students.

2. To evaluate the styles of coping among medical students.

3. To determine the psychopathological factors among medical students.

4. To determine differences in both gender.

5. To determine adaptive and maladaptive coping styles of students.

6. To find the association between psychopathological symptoms with emotional intelligence. 


\subsection{Hypotheses}

1. Higher scorers on emotional intelligence scale have least possibility to develop psychopathological symptoms.

2. Low emotional intelligence students have more psychopathological traits.

3. Poor emotional intelligence leads to maladaptive coping styles.

4. Emotional intelligence is high in female as compared to male.

5. Comorbidity of psychopathology symptoms lowers the threshold of emotional intelligence

\section{Materials and Methods}

The target populations were the student of public and private medical colleges of district Peshawar. The study comprising of 200 students randomly selected from public and private medical colleges between the ages range of 18-25 years of both the gender. The samples were taken from four medical colleges i.e. Khyber Medical College (KMC), Khyber Girls Medical College (KGMC), Pak International Medical College (PIMC) \& Rahman Medical College (RMC). The age of the students was 18-25 years which were included in the study. The 200 (100 boys and 100 girls) participant were selected from medical colleges of district Peshawar both public and private. A detailed demographic sheet was used for the current study. The sheet contains name, age gender, father income, college and address.

\subsection{Instrument}

Emotional intelligence scale (SRMEI) it was translated and validated in Pakistani culture [11]. It is comprised of 60 items consisting of three subscales ( Interpersonal capabilities ,Emotional self -Awareness scale ,Emotional self -Regulation).it is a 5-point scale with five responses categories with the highest value of 5 for Always ,4 for Often ,3 for Sometimes, 2 for Rarely, and 1 for Never. Higher score show higher level of Emotional Intelligence and lower scores indicate lower level of emotional intelligence. Scores can range from 60 to 300. Emotional Self-Regulation Scale (ESRS) consists of 3 positively phrased and 24 negatively phrased items. The score on this subscale ranged from the minimum 21 to the maximum 105.Interpersonal Skills Scale (ISS) consists of 11 positively phrased and 1 negatively phrased items. Items number $9,10,11,20,21,22,31,32,33,42$, and 43 while 41 is negatively phrased. The score range from these subscales is from the minimum 12 to the maximum 60 .Alpha value is 0.90 [11 the "Brief cope inventory [12] was used for data collection. The inventory comprised of 28 items with four point likert scale ( $1=\mathrm{I}$ have not been doing this at all , $2=\mathrm{I}$ have been doing this a little bit, $3=\mathrm{I}$ have been doing this most often and, 4= I have been doing this all the time). Higher score indicates greater coping by the respondents. The questionnaire covered 14 subscales, "active coping, planning, acceptance, denial, selfdistraction, use of substance, use of emotional support, use of instrumental support, behavioral disengagement, venting, positive reframing, humor, religion, and selfblame". For the sake of better understanding these dimensions were divided into four categories i.e. Adaptive (Problem-focused coping, Positive coping), Non Adaptive (Active avoidance coping and Religious and Denial coping).

Psychopathic Deviation; The original scale of MMPI developed in the late 1930 s and early $1940^{\mathrm{s}}$ it were translated into urdu version [13]. The Pd scale measured the resemblance to a group of individuals whose foremost problem falsehoods in their absences of profound emotional responses. Their incapability on the way to yield commencing proficiencies, and their neglect of group standards. It consists of 50 items with true -false category. The scoring range $(0,1)$ of $\mathrm{pd}$ scale the raw score were converted into standardized scores (T score) using suitable norm table as providing in MMPI. Score 70 or higher is normally taken as the cutoff point designed for the credentials of psychopathic deviate [13]

\subsection{Procedure}

The administrative officials of various colleges which were included in the present study were contacted and authority permission was taken from them. The whole research aim was explained to them and they had been assured that collected data were only used for research purpose. The booklet containing form A which included all demographic information while form B included three questionnaire i.e. Emotional intelligence scale of Urdu version, Brief cope scale Urdu version, and MMPI scale of psychopathic Deviation. The respondent was assured about the confidentiality of the information provided by them. For administration there were no time limits. Participants were helped in case of any trouble by the examiner. From different medical colleges 200 self-reports measures were filled by the student. The participants were acknowledged at the end.

\section{Results}

The results section begins with the presentation of descriptive statistics of demographic characteristics of the sample. This analysis used to describe the information regarding the Gender, age, educational background, father income, and three scales i.e. Emotional Intelligence, Brief cope inventory ,and Psychopathic deviation. 
Table 1. Demographic Information $(\mathrm{N}=200)$

\begin{tabular}{llll}
\hline $\begin{array}{l}\text { Demographic } \\
\text { Variables }\end{array}$ & Categories & $N$ & $\%$ \\
\hline Gender & Male & 117 & $57.4 \%$ \\
\cline { 2 - 4 } Age & Female & 83 & $40.7 \%$ \\
\hline \multirow{4}{*}{ Colleges } & $15-20$ & 29 & $14.2 \%$ \\
\cline { 2 - 4 } & $21-25$ & 170 & $83.3 \%$ \\
\cline { 2 - 4 } & $\begin{array}{l}\text { Total students } \\
\text { from Public } \\
\text { medical colleges }\end{array}$ & 104 & $51 \%$ \\
\cline { 2 - 4 } Fotal students & $\begin{array}{l}\text { Tota } \\
\text { from Private } \\
\text { medical colleges }\end{array}$ & 96 & $47 \%$ \\
\hline \multirow{3}{*}{ Father income } & 550000 & 55 & $27.5 \%$ \\
\cline { 2 - 4 } & $51000-75000$ & 55 & $27.5 \%$ \\
\cline { 2 - 4 } & $>75000$ & 90 & $45 \%$
\end{tabular}

Note: 200 male and female participants of four medical colleges, two public and two private

Table1 represents the demographic characteristics of all the respondents $(\mathrm{N}=200)$.four variable were selected for demographics information I-e gender, age, colleges and father income with categorization and percentages.

Table 2. Undergraduates' students of medical colleges' Aggregate levels of Emotional intelligence and its sub factors, Brief Cope Inventory and Psychopathic Deviate $(\mathrm{N}=200)$

\begin{tabular}{lll}
\hline Scales & M & SD \\
\hline EI & 186.2 & 25.642 \\
PEI & 98.335 & 17.116 \\
NEI & 87.87 & 17.2009 \\
BCI & 70.55 & 9.575 \\
PD & 57.66 & 9.243 \\
\hline
\end{tabular}

Note: EI=emotional intelligence; PEI=positive emotional intelligence; NEI=negative emotional intelligence; $B C I$; brief cope inventory; $P D=p s y c h o p a t h i c$ deviation

Results in table 2 represents mean and Standard Deviation of all three main scales with subscales. The mean of emotional intelligence $(M=186.2 \pm 25)$ were higher as compared to brief cope inventory and psychopathic deviation. While the BCI and PD scale of mean and standard deviation as represent with half of sample. $(\mathrm{M}=70.5 \pm 9.5 ; \mathrm{M}=57.6 \pm 9.2)$

Table 3. Relationship between Negative Emotional Intelligence and Brief Cope Inventory. ( $\mathrm{N}=200)$

\begin{tabular}{llll}
\hline \multirow{2}{*}{ Scales } & $\begin{array}{l}\text { Negative } \\
\text { Emotional } \\
\text { Intelligence } \\
\text { Score }\end{array}$ & $\begin{array}{l}\text { Total } \\
\text { Score Of } \\
\text { Brief } \\
\text { Cope } \\
\text { Inventory }\end{array}$ \\
\hline $\begin{array}{l}\text { Negative } \\
\text { emotional } \\
\begin{array}{l}\text { intelligence } \\
\text { score }\end{array}\end{array}$ & $\begin{array}{l}\text { Pearson } \\
\text { Correlation }\end{array}$ & 1 & .027 \\
\cline { 2 - 4 } & Sig. (2-tailed) & .706 \\
\cline { 2 - 4 } & $\mathrm{N}$ & 200 & 200 \\
\hline
\end{tabular}

\begin{tabular}{llll}
\hline $\begin{array}{l}\text { Total score of } \\
\text { brief cope } \\
\text { inventory }\end{array}$ & $\begin{array}{l}\text { Pearson } \\
\text { Correlation }\end{array}$ & .027 & 1 \\
\cline { 2 - 4 } & Sig. (2-tailed) & .706 & - \\
\hline Note: $p<.05$ & & &
\end{tabular}

The results in table 3 illustrates that the two variable and its significant relationships. The calculated value of negative emotional intelligence and brief cope inventory $(\mathrm{r}=.706)$ which showed strong relationship among variable. The $p$ at .05 level was $(\mathrm{p}<.02)$ which indicates significant correlation between two variable i-e negative emotional intelligence and brief cope inventory. T-test was used for comparing independent sample. Table no 4 represented comparison among male and female on emotional intelligence scale. It showed that $t$ value $(-2.363)$ was less than from $\mathrm{p}$ value at $0.019(\mathrm{p}<.05)$.so it mean there is statistically significant difference between two groups.

The table 5 indicates results of the two variable and its relationships. The significance level at .05 level was greater $(\mathrm{p}=.156)$ which indicates no significance relationships between two variable.

Table 5. Correlation between Emotional Intelligence and Psycopathetic Deviation ( $=200)$

\begin{tabular}{llll}
\hline Description & & EI & PD \\
\hline $\begin{array}{l}\text { Total score of } \\
\text { emotional } \\
\text { intelligence }\end{array}$ & $\begin{array}{l}\text { Pearson } \\
\text { correlation }\end{array}$ & 1 & .101 \\
\cline { 2 - 4 } & Sig. (2-tailed) & .156 \\
\cline { 2 - 4 } & $\mathrm{N}$ & 200 & 200 \\
\hline \multirow{3}{*}{$\begin{array}{l}\text { Psycopathetic } \\
\text { deviation }\end{array}$} & $\begin{array}{l}\text { Pearson } \\
\text { correlation }\end{array}$ & \multicolumn{1}{l}{10} & 1 \\
\cline { 2 - 4 } & Sig. (2-tailed) & .15 & \\
\cline { 2 - 4 } & $\mathrm{N}$ & 200 & 200 \\
\hline
\end{tabular}

Note: $p>.05$

The table no 6 showed the correlation between psychopathic deviate and negative emotional intelligence the results showed that $(\mathrm{r}=.194 * *)$ have strong relationships between two variables. The significant level at .01 $(\mathrm{p}=$. 006) which showed significant relationship of two variable.

The finding in table 7 of the regression analysis shows a weak positive relationships $(\mathrm{R}=.101)$ between independent variable psychopathic deviate and dependent variable emotional intelligence. $\mathrm{R}$ square value showed R.01 that there is insignificant change which in turn tells us to the whole population that result can be generalized in analysis of variance table $\mathrm{F}$ value (2.027) and $\mathrm{p}$ value $(\mathrm{p}<.156)$ which is high value from .05 level in coefficient table $(\beta=.101$, $\mathrm{t}=1.424)$ with $\mathrm{p}$ value (.000) which is less then at .05 level there is association between independent and dependent variable. 
Table 6. Correlation between Negative Emotional

Intelligence and Psychopathic deviation $(\mathrm{N}=200)$

\begin{tabular}{llll}
\hline \multirow{2}{*}{ Description } & Ptd1 & $\begin{array}{l}\text { Negative } \\
\text { emotional } \\
\text { intelligence score }\end{array}$ \\
\hline \multirow{2}{*}{ Ptd1 } & $\begin{array}{l}\text { Pearson } \\
\text { Correlation }\end{array}$ & 1 & $.194^{* *}$ \\
\cline { 2 - 4 } & Sig. (2-tailed) & .006 \\
\cline { 2 - 4 } & $\mathrm{N}$ & 200 & 200 \\
\hline $\begin{array}{l}\text { Negative } \\
\text { emotional } \\
\text { intelligence } \\
\text { score }\end{array}$ & \begin{tabular}{l} 
Pearson \\
\cline { 2 - 4 }
\end{tabular} & Sig. (2-tailed) & .006 \\
\cline { 2 - 4 } & $\mathrm{N}$ & 200 & 200 \\
\hline
\end{tabular}

Note: **0.01 level (2-tailed) Correlation is significant.

Table 7. Regression Analysis of Emotional Intelligence and Psychopathic Deviation ( $\mathrm{N}=200)$

\begin{tabular}{lllll}
\hline \multicolumn{5}{c}{ Model Summary } \\
\hline Model & $\mathrm{R}$ & R Square & $\begin{array}{l}\text { Adjusted R } \\
\text { Square }\end{array}$ & $\begin{array}{l}\text { Std. Error of } \\
\text { the Estimate }\end{array}$ \\
\hline 1 & $0.101^{\mathrm{a}}$ & .010 & .005 & 25.57679 \\
\hline
\end{tabular}

Note: a. Predictors: (Constant), ptd1; b. Dependent

Variable: total score of emotional intelligence

Table 7a.ANOVA

\begin{tabular}{lllllll}
\hline \multicolumn{7}{c}{ ANOVA } \\
\hline \multirow{2}{*}{ Model } & $\begin{array}{l}\text { Sum of } \\
\text { Squares }\end{array}$ & Df & $\begin{array}{l}\text { Mean } \\
\text { Square }\end{array}$ & F & Sig. \\
\hline \multirow{2}{*}{$\begin{array}{l}\text { Regression } \\
\text { Residual }\end{array}$} & 1325.88 & 1 & 1325.88 & 2.03 & $.156^{\mathrm{b}}$ \\
& Rotal & 129526.12 & 198 & 654.172 & & \\
\hline
\end{tabular}

Note: a. Dependent Variable: total score of emotional intelligence. b. Predictors: (Constant), ptd1

\section{Discussion}

This research was primarily aimed at finding the relationship of emotional intelligence, coping styles and psychopathic deviate among medical students at district Peshawar. The finding reveals that under grates of medical students have moderate to high level of emotional intelligence, coping styles and psychopathic deviation. The finding also suggested that negative emotional intelligence and psychopathic deviation have positive relationships .The present study also suggestive of emotional intelligence have positive relationship with coping styles. It was hypothesized that poor emotional intelligence leads to maladaptive coping styles. The present study used Pearsoncorrelation that there was a weak positive relationship among variable.

The second hypothesis of the present was that emotional intelligence is high in female as compared to male. Independent sample $\mathrm{t}$ test presented a statistically significant relationship among the two groups. It confirmed that female had high emotional intelligence as compared to male. The third hypothesis of the current study that higher scorer on emotional intelligence scale have least possibility to develop psychopathological symptoms. The result of the study did not show significant Pearson correlation in this respect.

The fourth hypothesis stated that low emotional intelligence have more pathological symptoms. It also confirmed from the results by using Pearson correlation that there is statistically significant association among variable. The final hypothesis of the study was that comorbidity of psychopathological symptoms lowers the threshold of emotional intelligence. From coefficient analysis and regression analysis there was significant relationship between variable.

A wide view of literature reviewed supported the finding. The following discussion is built on these finding. The study revealed that students who have low emotional intelligence showed high psychopathological characteristics. Psychopaths are totally lack empathy to deficits in emotion recognition and disappointment. The present study demonstrate that female have high emotional intelligence as compared to male. This finding was consisted with the study conducted that girls have better ER then men [14].

A similar study was conducted and it was a correlational study which found association among different regulatory strategies' of emotion including acceptance, avoidance, difficulty resolving, reevaluation, meditation and overpowering and psychopathological signs [9]. Whereas our study focused on broaden aspects of emotional intelligence and psychopathic deviation. Another study was conducted and compared 20 criminal psychopaths with 19 non psychopaths [15]. The hypothesis of the study does not supported by results that psychopathy have negative correlation with emotion perception and emotion regulation. The finding of this study contrary to above research, which documented that low emotional intelligence students have more psychopathological characteristics.

This research revealed that negative emotional intelligence has weak relationship with brief cope inventory. It is consistent with the results of research conducted and reported that in a group of adolescent, capability to cope and control emotion was negatively associated with use of nonproductive coping approaches [16]. It was discovered that high EI predicated the use of adoptive styles during the experience of not only stress but sadness anger, fear, shame, jealousy .while maintain the experience of joy 
[10]. Similar to this study the results of the current data indicate that here is significance relationship amongst variable i-e emotional intelligence and coping styles. The study reported that female participants had high score on interpersonal emotional intelligence than male [17]. The present study stated that emotional intelligence of female $(\mathrm{M}=191.22 \& \mathrm{SD}=18.38)$ is more than male $(\mathrm{M}=182.63 \& \mathrm{SD}=29.29)$. It was demonstrated that better health is highly associated with higher emotional intelligence. Contrary to this study, the present study does not compare Emotional Intelligence with health [18].

The study observed that there is more enhanced suicidal ideation among those low in controlling emotions. The present study of hypothesis is that those who have low emotional intelligence have more psychopathological symptoms [19]. The results indicate from correlational analysis that there are strong relationships between low level of emotional intelligence and psychopathic characteristics. The problem -focused coping and non-productive coping has relationships between behavior with emotional management strategy, recognition, expression and understanding of emotions. In consistent with the above study, regression analysis and coefficient analysis of Emotional Intelligence and Brief Cope inventory showed significant association [20].

It was reported that psychopaths are supposed to be lacking in identifying other emotions as well that overall EI had significant positively associated with all psychopathological measures of both gender [21]. It was also reported that alexithymia is positively associated to secondary psychopathology [22]. Whereas, similar to the above study the present study results indicated that there was positive relationships among emotional intelligence and psychopaths. The present study showed the psychopathology of medical students the total mean of both gender were 57.66 \& and standard deviation of 9.24. The study conducted on two cross sectional temporal meta type of analysis to find generational psychopathology among young American college students [14]. Young people had scored higher (average $\mathrm{d}=1.05$ ) including $\mathrm{Pd}$ (psychopathic deviate). The present study reported from 200 participants of medical students that low emotional intelligence has more pathological characteristics. It was investigated that criminal behavior can be predicated through emotional intelligence from a life span perspective view of psychopathy [23]. The study investigated emotional disorder through combined consequences of trait emotional intelligence, mindfulness, and the irrational ideals. A sequence of hierarchical regression verified that trait EI is a more potent predictor of psychopathology than mindfulness and irrational belief mixed [24]. The prevailing study anticipated that those who've pathological symptoms have low emotional intelligence tendencies.

It was also suggested that the effect of emotional intelligence on academic achievement facilitated by adjustment to university [25]. The present study does not compare the Emotional intelligence with Academic achievement. It was stated that psychological necessities \& healthiness have a specific significance in life of medical students. This research examines the association among healthiness and emotional intelligence of medical students in Yazd University [26]. It was predicted that there was positively association among healthiness and emotional intelligence. The present study does not compare EI with general health of the medical students.

A cross sectional analytical study was conducted in India on emotional intelligence of doctors and medical students, the mean score $(\mathrm{M}=124.4 \&$ sd $=12.8)$ [27]. While the present studys'mean was $(\mathrm{M}=186.20$ \& $\mathrm{SD}=25.64)$. The study was conducted on the association among academic achievement and EI of medical students. Multiple regression analysis showed a statistically significant positively correlation among EI and academic achievement of medical students $(\mathrm{r}=0.246 \mathrm{p}=.000)$ [28]. The present study also showed that emotional intelligence and Brief cope inventory have a positive linear relationship $(\mathrm{r}=.052, \mathrm{p}=.461)$ which is high value from 0.05 level.

The study stated the correlation among EI \& coping styles with stress. The data showed EI had positive correlation with coping styles [29]. The present study also showed that emotional intelligence and coping styles among medical students have a weak positive relationship.

\section{Conclusion}

To conclude, the findings of the study suggest that undergraduates in medical colleges of Pakistan have moderate to high levels of emotional intelligence, coping styles and psychopathological traits. Emotional intelligence according to the scales utilized in the research, As per general perception that prevails in the Pakistani society that males have low level of emotional intelligence as compared to female.as coping styles also high in female as compared to male. While the third scales used in the study indicates from the results that psycopathetic traits are more in male as compared to female.

\section{Limitation and suggestion:}

Limitations include resource, time constraints, convenient sample size so cannot be generalized to the 
whole population. This study can further elaborated to find out other related factors like behavior and attitudes in future. Due to the enormous amount of available scales for emotional intelligence, coping, and psychopathology based on different theoretical conceptualizations, it is recommended that future research use qualitative measures to compare results. In addition, EI was measured by a global score. This global scored was applicable for the Current research which designed to observe whether a general facilitated relationship existed among coping styles, EI, and psychopathology. However, now that it has been shown that a mediating effect exists. Undergraduate medical students are asset for our future. We highly praise the exploration of emotional intelligence, coping strategies and mental illness among medical students.

\section{Implication}

Despite some of the limitation of this there is certain implication of research in clinical psychology perspective. Though the results obtained are not definitive due to the correlational research Design, there are several implications that can be drawn from this study. This study supports current literature proposing emotional intelligence as a protective factor against Psychopathology. From a functionalist perspective this relationship makes sense. Emotions guide behavior and they are used as information to help the individual achieve goals. Therefore, deficits in emotional intelligence would have a negative effect on the individual's ability to make goal-directed decisions. Although it has not been confirmed that this relationship is causal, interventions aimed at improving emotional intelligence can be used to further prevent and treat mental illness. Training to improve emotional intelligence has already been encouraged in the fields of education and business. These activities should be improved and supported given the benefits.

\section{References}

[1]. Lewis, N. J., Rees, C. E., Hudson, J. N., \& Bleakley, A. (2005). Emotional intelligence medical education: measuring the immeasurable? Advances in Health Sciences Education, 10(4), 339-355.

[2]. Arora S, Ashrafian H, Davis R, Athanasiou T, Darzi A, Sevdalis N.(2010). Emotional intelligence in medicine: a systematic review through the context of the ACGME competencies. Med Edu; 44:749-64.

[3]. Azimi, S., AsgharNejad Farid, A. A., Kharazi Fard, M. J., \& Khoei, N. (2010). Emotional intelligence of dental students and patient satisfaction. European Journal of Dental Education, 14(3), 129-132.

[4]. Faye A, Kalra G, Swamy R, Shukla A, Subramanyam A, Kamath R.(2011). Study of emotional Intelligence and empathy in medical postgraduates. Indian J Psychiatry; 53:140-4.

[5]. Taylor, G. J. (2004). Alexithymia: 25 years of theory and research. Emotional Expression and health. Advances in theory, assessment and clinical Applications, 137-153.

[6]. Serrat, O. (2017). Understanding and developing emotional intelligence. In Knowledge Solutions (pp. 329-339). Springer Singapore.

[7]. Folkman, S., Lazarus, R. S., Dunkel-Schetter, C., DeLongis, A., \& Gruen, R. (1986). Dynamics of a stressful encounter: Cognitive appraisal, coping, and encounter outcomes. Journal of Personality and social psychology, 50(5), 992.

[8]. Cooke, D. J., Hart, S. D., Logan, C., \& Michie, C. (2012). Explicating the construct of psychopathy: Development and validation of a conceptual model, the Comprehensive Assessment of Psychopathic Personality (CAPP). International Journal of Forensic Mental Health, 11(4), 242-252.

[9]. Aldao, A., Nolen-Hoeksema, S., \& Schweizer, S. (2010). Emotion-regulation strategies across Psychopathology: A meta-analytic review. Clinical psychology review, 30(2), 217-237.

[10]. Mikolajczak, M., Nelis, D., Hansenne, M., \& Quoidbach, J. (2008). If you can regulate sadness, you can probably regulate shame: Associations between trait emotional intelligence, emotion regulation and coping efficiency across discrete emotions. Personality and individual differences, 44(6), 1356-1368.

[11]. Khan, R.A, Kamal, A. (2010). Manual of Self Report Measure of Emotional Intelligence. National institute of Psychology Quaid- Azam University. Islamabad, Pakistan.

[12]. Akhtar, M. (2005). Coping strategies and its relationship with stress and time demands among university students. Unpublished M.Phil. Thesis. National Institute of Psychology, Quaid-e-Azam University, Islamabad.

[13]. Mirza L. (1977). The Minnesota multiphase personality inventory. Manual adapted for Pakistan, Lahore. Psychol Aids.

[14]. Twenge, J. M., Gentile, B., DeWall, C. N., Ma, D., Lacefield, K., \& Schurtz, D. R. (2010). Birth cohort increases in 
psychopathology among young Americans, 1938-2007: Across temporal meta-analysis of the MMPI. Clinical psychology review, 30(2), 145-154

[15]. Pham, T. H., Ducro, C., \& Luminet, O. (2010). Psychopathy, alexithymia and emotional intelligence in a forensic hospital. International Journal of Forensic Mental Health, 9(1), 24-32.

[16]. Austin, E. J., Saklofske, D. H., \& Mastoras, S. M. (2010). Emotional Intelligence, coping and exam-related stress in Canadian undergraduate Students. Australian Journal of Psychology, 62(1), 42-50.

[17]. Alumran, J. I., \& Punamäki, R. L. (2008). Relationship between Gender, Age, Academic Achievement, Emotional Intelligence, and Coping Styles in Bahraini Adolescents. Individual Differences Research, 6(2), 104119.

[18]. Schutte, N. S., Malouff, J. M., Thorsteinsson, E. B., Bhullar, N., \& Rooke, S. E. (2007). A meta-analytic investigation of the relationship between emotional intelligence and health. Personality and individual differences, 42(6), 921-933.

[19]. Ciarrochi, J., Deane, F. P., \& Anderson, S. (2002). Emotional intelligence moderates the relationship between stress and mental health. Personality and individual differences, 32(2), 197-209.

[20]. Downey, L. A., Johnston, P. J., Hansen, K., Birney, J., \& Stough, C. (2010). Investigating the mediating effects of emotional intelligence and coping on problem behaviors in adolescents. Australian Journal of Psychology, 62(1), 20-29.

[21]. Visser, B. A., Bay, D., Cook, G. L., \& Myburgh, J. (2010). Psychopathic and antisocial, but not emotionally intelligent. Personality and Individual Differences, 48(5), 644-648.

[22]. Lander, G. C., Lutz-Zois, C. J., Rye, M. S., \& Goodnight, J. A. (2012). The differential Association between alexithymia and primary versus secondary psychopathy. Personality and Individual Differences, 52(1), 45-50.

[23]. Curci, A., Cabras, C., Lanciano, T., Soleti, E., \& Raccis, C. (2017). What is over and above psychopathy? The role of ability emotional intelligence in predicting criminal behavior. Psychiatry, Psychology and Law, 24(1), 139151.

[24]. Petrides, K. V., Gómez, M. G., \& PérezGonzález, J. C. (2017). Pathways into psychopathology: Modeling the effects of trait emotional intelligence, mindfulness, and irrational beliefs in a clinical sample. Clinical Psychology \& Psychotherapy.

[25]. Garg, R., Levin, E., \& Tremblay, L. (2016). Emotional intelligence: impact on postsecondary Academic achievement. Social Psychology of Education, 19(3), 627-642.

[26]. Baghianimoghadam, M. H., Sabzemakan, L., Hadavandkhani, M., Ardian, N., \& Saleh Manshadi, S. (2015). The Relationship between General Health and Emotional Intelligence among Students in Yazd University of Medical Sciences. Caspian Journal of Health Research, 1(1), 55-62.

[27]. Ravikumar, R., Rajoura, O. P., Sharma, R., \& Bhatia, M. S. (2017). A Study of Emotional Intelligence Among Postgraduate Medical Students in Delhi. Cureus, 9(1).

[28]. Naeem, N., van der Vleuten, C., Muijtjens, A M., Violato, C., Ali, S. M., Al-Faris, E. A., ... \& Naeem, N. (2014). Correlates of emotional intelligence: results from a multiinstitutional study among undergraduate medical students. Medical teacher, 36(sup1), S30-S35.

[29]. Noorbakhsh, S. N., Besharat, M. A., \& Zarei, J. (2010). Emotional intelligence and coping styles with stress. Procedia-Social and Behavioral Sciences, 5, 818-822.

[30]. Brenner, E. M., \& Salovey, P. (1997). Emotion regulation during childhood: Developmental, interpersonal, and individual considerations. Emotional development and emotional intelligence: Educational implications, 168-195.

[31]. Carver, C. S. (1997). You want to measure coping but your protocols too long: Consider the brief Cope. International Journal of Behavioral Medicine, 4 (1), 92-100.

[32]. Kunnanatt, J. T. (2004). Emotional intelligence: The new science of interpersonal effectiveness. Human

Development Quarterly, 15(4), 489-495

[33]. Lazarus, R. S., Folkman, S., \& Stress, A. (1984). Coping. Stress and emotion: A new synthesis, 5, 101-126.

[34]. Mayer, J. D., \& Cobb, C. D. (2000). Educational policy on emotional intelligence: Does it make sense?. Educational psychology review, 12(2), 163-183. 